\title{
The modern man: a revision of his definition and a new estimation of his emergence date
}

\author{
Hassen Chaabani \\ Hassen Chaabani was born the 07 / 09 / 1947 in Tunis (Tunisia). \\ He is Full Professor and research unit Director at Monastir University. \\ He is the Founder and the President of the Tunisian Association of Anthropology. \\ He is the Founder and the Editor in-Chef of the International Journal of Modern Anthropology. \\ Specialist in Human Genetics, Biological Anthropology and some cultural and religious \\ subjects, he wrote many articles and books. \\ Laboratoire de Génétique Humaine et d'Anthropologie, Faculté de Pharmacie, \\ 5000 Monastir, Tunisia. E.mail: hassen.chaabani@ fphm.rnu.tn
}

\begin{abstract}
In spite of important anthropological data stored up to date, the recent human evolution is still a subject of great controversy. Here I present a revision of the definition of modern man and an attempt to estimate the date of his emergence. The anatomical feature criterion cannot be considered as a rigorous criterion for identified modern human fossils from those of earlier Homo peoples. This identification could be carried out indirectly from analysis of cultural products and, if possible, directly by ancient DNA analysis. During the last 20,000 years period, Homo peoples have shown a first real cultural progress, which reflects their possession of the superior level of potential intellectual aptitude that marks the definition of modern man. On the basis of this definition, in agreement with several anthropological basic data, I consider that the real modern man, Homo sapiens sapiens, emerged at about 20,000 years ago.
\end{abstract}

Key words : Definition of our genus and species, Timing of our species and sub-species divergence, Human evolutionary history. 


\section{Introduction}

Many different estimations of the date of the modern man emergence have been proposed, around $40,000-30,000$ or $60,000-50,000$ or $100,000-70,000$ years BP (Bräuer, 1984; Protsch, 1975; Thoma, 1973; Brace, 1964). At present, the date of about 120000 years BP is relatively more accepted because it corresponds to the age of earliest fossils with anatomically modern forms found in sub-Saharan Africa and in Levant (for review see Stringer, 2003). However, earlier date, estimated by a large interval between 150,000 and 300,000 years BP, was deduced from mitochondrial DNA (mtDNA) analysis (Cann et al., 1987). This analysis, in which the place of the modern man emergence was also proposed within a hypothesis designated "Out-of-Africa", has been criticized and reviewed by many authors (e.g., Hedges et al., 1992; Maddison et al., 1992, Excoffier and Langaney, 1989). Later many subsequent studies have generated more reliable haplotype trees for mtDNA, Y-chromosomal DNA, X-linked DNA and several autosomal DNA regions (Ingman et al., 2000; Hammer et al., 1998; Harris and Hey, 1999; Kaessman et al. 1999; Zhang and Rosenberg, 2000; Harding et al., 1997).

In 2002 Templeton has grouped basic data of these studies and reanalyzed them using only one common method. Results obtained have given some corrections on human expansion dates and if agree with the classic Out-of-Africa hypothesis, they differ in considering expansions as resulted in interbreeding and not replacement. In addition, Templeton study is not limited to the emergence and expansions of modern humans but extended back to any point in Homo evolutionary history. He proposes a first Out of Africa expansion accomplished by Homo erectus at about 1700,000 years ago shown by fossil data. A second Out of Africa expansion accomplished at about $840,000-420,000$ years ago shown by haemoglobin $\beta$ and regions on chromosome 16. A third Out of Africa expansion accomplished at 150,000 - 80,000 years ago shown by mtDNA and Y-DNA. Finally, a back to Africa, it is an expansion from Asia accomplished at 30000 years ago shown by Y-DNA and the haemoglobin $\beta$ locus. 
Thus, Templeton has putted the classic Out-of-Africa hypothesis in a new broad context. These four expansions could be accepted if we accept the method used by Templeton; while, the determination of species and sub-species of Homo peoples who would accomplish each of these expansions presents a thorny problem.

In this study I present a revision of the definition of the genus, the species and sub-species of modern humans. In the light of this revision and on the basis of many arguments I propose a new estimation of the date of their emergence.

\section{Unique and recent origin for all of us}

Broadly speaking, two opposing models have been proposed to explain the origin of modern humans: the "single origin" model and the "multiregional origin" model. The former suggests that all present human populations descend from a single ancestral population of modern humans who, spread throughout the earth, having completely replaced the preceding archaic populations. Whereas the latter assumes that there was no single origin for modern humans, but there was a continuous transition among regional populations. Namely, there was independent appearance of modern traits in different areas at different times.

The model of the single origin of all modern humans has been strongly supported by genetic studies, which have shown a surprisingly small amount of genetic variation, noted throughout all present human populations (e.g., Hammer,1995; Denaro et al., 1981). These genetic data show that our origin is not only unique but also recent and consequently the model of single origin is expanded in a general theory, the theory of the unique and recent origin of all modern humans. This theory could be considered within the most precious conclusions reported in the last $20^{\text {th }}$ century. In fact, it comes to support the human unity notion, which has been putted forward, since the $18^{\text {th }}$ century, by Buffon, the true founder of human natural history. 
I can here present his expression translated from French as fellows: « The man, white in Europe, black in Africa, yellow in Asia and red in America, is only the same man dyed by the climate color ». The single recent origin theory is also in accordance with linguistic data. In fact, modern linguists put forward the view that all current languages would originate from a unique and recent ancestral one (Ruhlen, 1998; Shevoroskin, 1989, 1990). As the multiregional model in its original formulation is opposed to the quoted genetic data, some variants of this model are presented. The recent one, intermediate between the two models, retained the concept of a single evolving species, but argue that modern forms expanding from the geographic origin have mixed with archaic forms (Templeton, 2002). However, recent results on ancient DNA analysis are not in favor of this intermediate model. They show that mtDNA of Cro-Magnon specimens as well as that of living European samples differ from that of Neanderthal specimens. Namely, Neanderthals could not contribute to the current European gene pool (Caramelli et al., 2003).

As I will show in the following pages my thesis relating to the emergence of modern man is within the single recent origin theory. To avoid all confusion and vagueness over this theory, two remarks must be pointed out. First, as this theory, is supported by genetic and linguistic data relating to current human populations, it must concern only modern humans without involving earlier Homo peoples. Second, I think that it is improper to link this general theory with the determination of the place and the time of modern man emergence that are still a controversial topic (Chaabani, 2002).

\section{Redefinition of the genus Homo: Homo erectus is the first Homo}

Since more than a century, classic human paleontologists have begun the research of hominid fossils for deducing from their examination possible explanations on our origin. Unfortunately, these fossils are very scarce and often discovered at sparsely periods in incomplete states. Thus, each of these scarce incomplete fossils has been analyzed in a separated study subject to mistake and imagination. I can summarize the main considerations emanating from these classic studies and concerning the principal steps of the human evolutionary history as follows: 
Australopithecus < Homo habilis $<$ Homo erectus $<$ Homo Heidelbergensis $<$ Homo sapien

New observations and rigorous analyses contrast these classic considerations: First, the so called, habilis does not belong to the human lineage. Second, the disappearance of a species just after given a more evolved species is not categorical. In fact the age of some erectus specimens show that erectus had seen life until about 30,000 years. Third, such a classification of species within Homo genus established on the basis of morphological features could not be maintained. In fact, the first note is based on the finding of the Wood and Collard study (1999). These two eminent modern paleo-anthropologists have presented a meticulous general revision of anatomical features of hominid fossils. From rigorous comparative analyses they concluded strongly that the two fossils called Homo habilis and Homo rudolfensis do not in fact belong to the genus Homo, but they belong to a non-human ape species. Thus, they consider that early individuals belonging to the genus Homo are those who, designated Homo erectus, had emerged in sub-Saharan Africa at about 1800,000 years ago.

This conclusion is strongly supported otherwise by two other eminent modern paleo-anthropologists Bramble and Lieberman (2004). They have shown that Homo erectus is the first who have the anatomical features responsible to the possession of the endurance running ability and that of the real upright body form. These anatomical features (about 26 features) absent in all predecessors of Homo erectus differentiate Homo peoples. Consequently, the bipedal gait restricted to walking, classically considered as a humanization criterion, would not be supported any more. In fact, this criterion could be an ancient adaptation, which probably existed even before the divergence between apes and humans at about 5 million years ago. The case of fossil Orrorin tugenensi, 6 million year old and that of "Toumai" Sahelanthropus tchadensis, 7 million year old, already adapted to the bipedal gait agree with this view. 
Considering all these recent data, I can define the Homo peoples as follows: "Peoples belonged to the genus Homo are those who possess the principal anatomical features of actual humans particularly those responsible to the real upright body form associated to the endurance running ability ". This definition could be reduced to only one sentence: "Homo genus has been created in the best elegant and upright form ".

\section{Revision of species determination within Homo genus}

As noted above, all Homo peoples must possess all principal anatomical features of present humans. For classing species within the Homo genus some classic anthropologists have used as criterion the secondary anatomical features particularly those of the skull as the facial structure. They have considered that these features present some variation from primitive state, with archaic features, to modern state, with modern features. However, many studies show that such a consideration is uncertain. Among these studies, I can quote the study of the anatomical examination of Inuits (Eskimos) and Aleuts (people living on the Aleut islands) by Laughlin (1963) who noticed that these peoples were extraordinarily similar to Homo erectus. Since, some comparative studies showed that important skeleton anatomical features of Homo erectus as the post-cranial skeleton are modern-human-like (e.g.,Spoor et al., 1994). Other studies showed that the secondary anatomical features particularly the skull traits do not present a distinct variation interval for each of erectus and sapiens species, but the two intervals often present some overlapping. For instance, some actual human individuals or populations as pygmies have a cranial capacity similar to that of Homo erectus. While others as Native Australians have protruding eyebrows as the erectus case.

In addition, if we follow these variable individual features since the beginning we note that Homo erectus specimens are not categorically with only the so-called primitive features. In fact, fossils of Peking and Java man in Asia are incomplete and cannot be considered as reliable. 
On the other hand, the most famous and complete early Homo erectus specimen found in Africa is the fossil of the "Turkana Boy" that shows, beside the prevailing primitive features, some advanced features (e.g., Gish, 1995). However, at about the half of the Homo people's existence, between 700,000 and 500,000 years ago, there is an almost equal mixture between primitive and advanced traits. This is supported by the fact that paleo-anthropologists are obliged to use phrases such "a curious mixture of primitive and advanced traits" or "a transitional form" with specimens dated within this period. This process by which modern features increase to detriment of primitive ones has continued until living humans in whom the so-called modern anatomical features reach a strong predominance but without complete disappearance of archaic features. This is also demonstrated by the fact that relatively recent Homo fossil specimens dated about 160,000 years ago and discovered recently in Ethiopia, present mainly modern anatomical features with yet some evident archaic traits (White et al., 2003). Even specimens considered anatomically modern as that of Skhul and Qafzeh, dated about 120,000 years ago, despite the predominance of modern traits, possess some archaic features, such as prominent brow ridges and large teeth (Klein, 1992).

In the light of these observations, it seems reasonable to consider that during all stages of the Homo people evolution the secondary anatomical features have not came under any suddenly important genetic changes. Rather, they are passed by a very slow variation during 1800000 years generally from predominance of archaic features to predominance of modern ones. However, this variation could be uncertain when not large period are considered, because this variation is very likely the consequence of a very slight uncertain sexual selection and / or the consequence of few and small genetic changes occurred spaced out during the long period of the Homo evolution. In any case, it is inconceivable to set limits within this variation of the secondary anatomical features for classing species inside the genus Homo. In other words, it is not possible to know if such slow and uncertain morphological variation is within-species variation or amongspecies variation. In addition, as notes Tattersall (1992), there is no direct relationship, indeed no consistent relationship at all, between speciation and morphological change. 
Support to all these considerations comes from an incompatibility noted between this morphological variation and that of ancient mtDNA sequences in Australians showing the uncertainty of this variation and its incapability of differentiate fossils belonged to different species of our genus. In fact, although anatomically modern, the morphologically robust specimens from Kow Swamp, between 8,000 and 15,000 years old, fall outside the range of skeletal metrics of living Australians, but they have similar mtDNA cluster with living Australians. While Lake Mungo 3 fossil, roughly 60,000 years old, is more similar anatomically to living humans, but it has divergent mtDNA sequence (Adcock et al. 2001; Relethford, 2001).

\section{Definition of modern man and advancement of a new hypothesis concerning his emergence date}

From what presented above, we can conclude that the anatomical studies are unqualified for leading to the differentiation or to the classification of species within our genus Homo. Namely, these studies do not permit to recognize fossils belonged to our species sapiens from those belonged to earlier Homo peoples. Thus, we must look for an adequate criterion that permits us to identify modern human's fossils. Everybody knows that modern humans differ from all being, including other Homo peoples, essentially by the superior level of their potential intellectual aptitude. Unfortunately, this criterion cannot be determined from the investigation of Homo fossils, but it could be determined indirectly from the vestige of their cultural products.

In Table 1, I present a global survey of the important cultural products carried by Homo peoples from the emergence of the earliest one, since 1800,000 years, until nowadays. This presentation shows four possible periods. During the earliest period between 1800,000 and 500,000 years ago, in addition of some behavioral actions as the use of fire, Homo peoples produced only one cultural product limited to bifacial stone tools. This poor cultural product carried out during a hung tract of time, about 1400,000 years, reflects the low potential intellectual aptitude of these peoples. 
As they are the firsts who have a real upright body form associated to the endurance running ability, I keep the designation of erectus as the species of these first Homo peoples. As stated above these peoples had all principal anatomical features of living humans and had a predominance of so-called archaic secondary anatomical features so I propose to them "primitives" as subspecies.

During the period 500,000 - 40,000 years ago, Homo peoples produced also only new stone technology the prepared core but during a shorter period. In addition, they began to have a preliminary funeral behavior (Carbonell et al., 2003). I believe that this ritual act reflects the possession of the first preliminary faculty of realizing important events such as the death. In other words, it seems that these peoples began to understand that one day they would die and thus they began to express some apprehension towards this event. According to this slight improvement in their mind and their behavior, it is reasonable to suppose that these peoples had carried general genetic changes few of which concern brain genes and permits the intellectual aptitude level to pass from "low" to "underneath average" (Table 1). As they are the first who began to make some disquiet towards violent passions as the death, I consider them as belonging to a new subspecies "inquietus". Their complete designation is Homo erectus inquietus and their divergence could be happened from Homo erectus in sub-Saharan Africa and other regions of the Old World.

During the relatively short period between 40000 and 20000 years, in addition of the manufacture of a new stone tool technology, Blade-based stone technology, Homo peoples presented their first artistic expressions. These peoples would diverge from Homo erectus inquietus people who lived at about 40000 years ago and having enough so-called modern anatomical features. In fact, the divergence of these peoples very likely concerns mainly molecular genetic changes whose those relating to the brain were relatively more important than those accomplished in the previous divergence, for moving up the intellectual aptitude level from "underneath average" to "average" (Table 1). 
These changes would mark the emergence of a new species to which I keep the designation "sapiens", literally means wise man, because he reaches a respectable level of the intellectual aptitude. As corresponding humans are the firsts who had began to express the art I consider them belonging to a sub-species "artist". CroMagnon type, appeared at about 30,000 years ago in Europe, could be considered as a regional race of these Homo sapiens artist peoples. Seeing that the earliest drawing art is found mainly in southern Europe, it seems that Homo sapiens artist diverged somewhere in regions of Middle East and southern Europe. However, other similar divergences in other regions, as East Asia, are possible (Table 2).

Taking the existence length and the number and the value of cultural innovations into account, the last 20000 years period appears strongly distinct from precedents. In fact, this period presents an obvious cultural progression with harmonious succession of innumerable extraordinary innovations started particularly by the acquisition of the complex spoken language (Table 2). This reflects the superior level of the potential intellectual aptitude of peoples who have seen life during this last period. Namely, these peoples possess the high degree of biological and physiological brain complexity that determines them as real modern humans. To these peoples, appeared at about 20000 years ago, I keep the scientific designation of our own species and sub-species, Homo sapiens sapiens. They diverged very likely from their predecessors, Homo sapiens artist people, belonging to the same species. This divergence involved only slight change in bodily physique. In fact, since the end of Pleistocene, which corresponds to the proposed date of Homo sapiens sapiens emergence, fossil investigation shows that humans were smaller than their immediate ancestors. In addition, they presented a difference in size between males and females significantly reduced in comparison with that of earlier humans (Foley, 1988). On the other hand this divergence is mainly associated to important genetic changes on brain genes responsible to moving up the intellectual aptitude level from "average" to "superior". Geneticists have begun to identify some of these brain genes as the RNA gene HAR1F that express during the cortical development and has evolved rapidly in humans (Pollard et al. 2006). 
The superior level of intellectual aptitude reflects the high degree of the brain complexity that could be estimate essentially by a high number of neurons and synaptic connections and perfection at the level of functional molecular factors. I consider this brain complexity as appeared in its complete high degree since the creation of the first modern humans and consequently it has not evolved in the course of time. It is the rate of know-how and knowledge that has evolved changing from time to time the manner and the intensity of the utilization of the potential aptitude of brain. Thus, this high degree of brain complexity presents a constant precious criterion, which marks strongly the definition of modern man, Homo sapiens sapiens, emerged at about 20000 years ago.

According to my hypothesis, the radiation of modern man towards the different world continents came off by population replacement. I consider that modern man emerged just at the end of an extinction period of all his predecessors. This extinction period, so proposed, coincides with the most terrible episode of the last glacial period between about 22,000 and 20,000 years BP (Lowell et al., 1995; Pons et al., 1991). Namely, this relatively long episode with dramatic, arid and cold climate is certainly the essential cause accountable for an important extinction of Homo peoples.

If appearance dates of different cultural products, presented in Table1 are generally accepted, that concerning the development of the complex spoken language needs some justification, which I will present with other enlightenment in the following pages. In addition, the Homo people classification and the timing of modern man emergence, so proposed above, sometimes go beyond what one can deduce from a so simple analysis of cultural products. In fact, my reasoning is also influenced and guided by other data that I cannot quote simultaneously and I prefer present them separately as arguments that contribute to the development of my thesis. 
Table 1. Hypothetical classification of Homo peoples

\begin{tabular}{|c|c|c|c|}
\hline $\begin{array}{c}\text { Date } \\
\text { in years BP }\end{array}$ & $\begin{array}{l}\text { Important new } \\
\text { cultural products }\end{array}$ & $\begin{array}{l}\text { Estimation of intellectual } \\
\text { aptitude level }\end{array}$ & \begin{tabular}{|} 
Designation of Homo \\
peoples emerged at the \\
beginning of each of four \\
distinct cultural periods
\end{tabular} \\
\hline 1800000 & - Bifacial stone tools & Low & Homo erectus primivitus \\
\hline $\begin{array}{l}500000 \\
400000\end{array}$ & $\begin{array}{l}\text { - Prepared core stone } \\
\text { technique } \\
\text { - Funeral preliminary } \\
\text { behaviour }\end{array}$ & Underneath the average & Homo erectus inquietus \\
\hline 40000 & $\begin{array}{l}\text { - Blade-based stone } \\
\text { technology } \\
\text { - Drawing products }\end{array}$ & Average & Homo sapiens artist \\
\hline 20000 & $\begin{array}{l}\text {-Microlith stone technology } \\
\text {-Artistic products } \\
\text {-Development of a complex } \\
\text { spoken language and a } \\
\text { social complexity } \\
\text {-Agriculture innovation } \\
\text {-Copper industry } \\
\text {-Invention of wheeled carts } \\
\text {-Bronze then Iron industry } \\
\text {-Writing innovation } \\
\text {-Recent known innovations }\end{array}$ & Superior & Homo sapiens sapiens \\
\hline
\end{tabular}

Table 2. Hypothetical evolution of Homo peoples in agreement with cultural development and ancient DNA analysis 
\begin{tabular}{|c|c|c|}
\hline $\begin{array}{c}\text { Date } \\
\text { in years BP }\end{array}$ & $\begin{array}{c}\text { Designation and evolution of } \\
\text { Homo peoples }\end{array}$ & Emergence and expansion regions \\
\hline
\end{tabular}

1800000

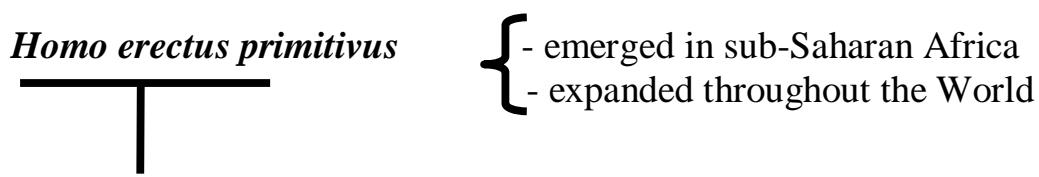

( Heidelberg type could be considered as a regional race of Homo erectus appeared at about 800,000 years ago and lived in Africa, Europe and Levant.)

500000

400000

40000

20000

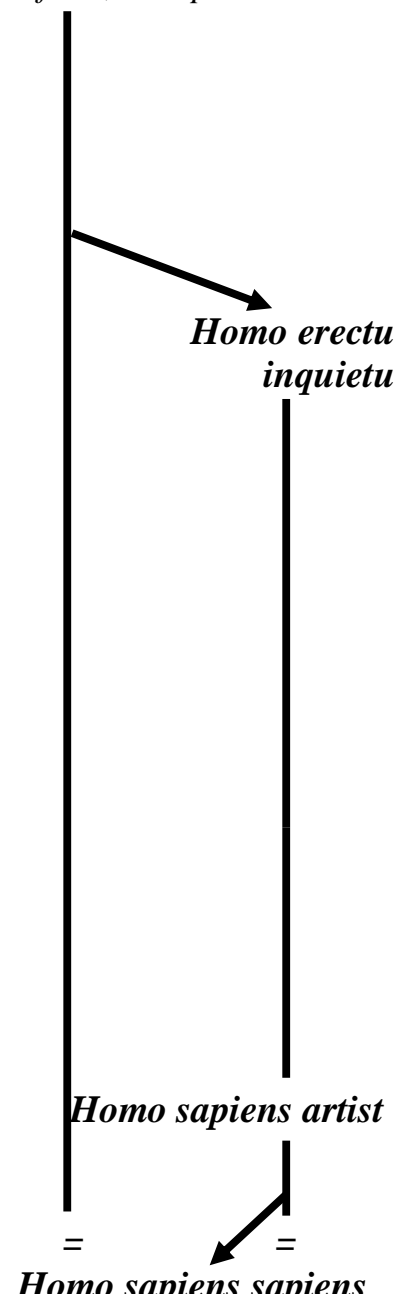

Homo sapiens sapiens

$$
\left\{\begin{array}{l}
\text { diverged in several possible } \\
\text { regions of the Old World } \\
\text { possible expansion }
\end{array}\right.
$$

- diverged,likely, in middle East and or in southern Europe and possible other regions as Asia.

- diverged in a unique region, probably the Yemen

- expansion by replacement throughout all the world 


\section{Arguments involved in the development of the present thesis}

\section{- Arguments from genetic data}

As I have expounded, the analysis of present-day patterns of genetic variation within and between living human populations points strongly to a single recent origin limited to modern man emergence. In agreement with this precious finding my hypothesis give a really recent date to modern man emergence estimated to about 20,000 years ago.

Since 1997, analysis of living human DNA was extended to that of human fossil ancient DNA when Krings and his collaborators have done with success the initial extraction of mtDNA from Neanderthal specimens from Feldhofer Cave in Germany. Results of this study as those of more recent studies ( Krings et al., 2000; Ovchinnikov et al., 2000, Caramelli et al., 2003 ) show that Neanderthals fall outside the range of living human genetic diversity. This is contrary to the view that considers Neanderthals as genetically related with the anatomically modern ancestors of current Europeans. But it agrees with my hypothesis in which I consider that Neanderthals do not belong to our own species, sapiens, rather present another subspecies of Homo erectus that we can designate Homo erectus neanderthalus. In addition, my hypothesis solves the disquieting question: how Neanderthals and modern humans lived together in the same regions and at the same period without mixture? According to my hypothesis the real modern man, Homo sapiens sapiens, emerged at the end of an extinction period of all his predecessors included Neanderthals.

As stated above the results of mtDNA analysis of Australian fossils (Adcock et al., 2001) show that Lake Mungo 3 fossil (60,000 year old) is anatomically similar to living humans, but it has divergent mtDNA sequences. This contrasts the courant view that considers all human fossils anatomically modern as those of modern humans. 
However, these results feet with my hypothesis that considers Lake Mungo 3 fossil does not belong to modern humans, Homo sapiens sapiens, but belongs to Homo erectus inquietus. My hypothesis agrees also with results of ancient mtDNA, which show that the anatomically modern European fossils, 24000 years old, fall well within the range of variation of today's humans (Caramelli et al., 2003). In fact, according to my hypothesis these fossils belonged to Homo sapiens artist, who is genetically relatively close to Homo sapiens sapiens except at the level of brain genes. In the coming years, other possible ancient DNA analysis relating to several nucleic sequences and done on more important number of specimens with different ages will provide more satisfactory tests towards my hypothesis. Thus, more developed ancient DNA analysis will complete and check the cultural product analysis for recounting the Homo people history.

Recent works (e. g. Wang et al., 2006; Voight et al., 2006) show an evident recent positive selection in the human genome. Wang and his collaborators (2006) suggest that events of this positive selection likely occurred in the last $10000-40000$ years. This agrees with my hypothesis where I consider that our sapiens species emerged at 40000 years BP with a sub-species artist and at 20000 years BP with our sub-species sapiens. In fact, the positive selection promotes the emergence of new phenotypes and can leave a set of telltale signatures in the genes under its influence, such as the rapid divergence of functional sites between species and the depression of polymorphism within species ( Kreitman, 2000; Bamshad and Wooding, 2003 ). In addition, authors of these works show a category of genes for which positive selection appears to have operated more intensely in the lineage leading to humans than in other lineages. These genes, often associated with behavior and brain development, are particularly relevant to understanding the evolution of biological traits as advanced cognitive abilities that distinguish our species and sub-species sapiens sapiens (for review see Vallender and Lahn, 2004). 


\section{- Arguments from archaeological data}

As stated above, my hypothesis is advanced in consequence of a revision of modern man definition and a global survey relating to the important cultural products of Homo peoples. Thus, my hypothesis is completely in agreement with the general archaeological context. In addition, it comes to resolve some questions that present disquieting puzzles. First, the Homo fossils, about 120,000 years old, often considered as that of modern humans, present an evident uncoupling of modern morphology from modern behavior. Namely, it is impossible to accept that the same modern man, who has done all known innumerable and extraordinary innovations during the last 20,000 years, had passed the previous 100,000 years of his existence producing mainly one simple technology of stone tool. Thus, according to my hypothesis all human fossils having more than about 20,000 years of age do not belong to the real modern humans Homo sapiens sapiens.

Second my hypothesis takes off another enigma, that of the transitional period between the Solutrean and the Magdalenian or between their equivalents outside Europe. In fact, in some caves, where the Palaeolithic is relatively quite presented, it is noted a layer which shows an absence of human tools. This layer is dated of about 17,500 years in Shanidar Cave in Iraq (Solecki, 1955) and of about 18,000 years in Abri Fritsch Caves in France (Allain, 1984). In addition, the meticulous study of the latter site confirms an observation, which has posed a problem since a century. It is the sudden and definitive disappearance of the refined Solutrean industry corresponding to a period during which the site seems deserted (absence of human tools). In addition, this period was followed by an appearance of another industry completely different and much less developed (Allain 1984). Namely a great bound backwards between Solutrean and initial Magdalenian or Badegoulian, appeared at about 17,500 years ago in Europe. According to my hypothesis, this period came quite after the period that I have considered as an extinction period, 22,000 - 20,000 years ago, and just before the arrival of the real modern humans to southern Europe very likely at 17,000 years ago from a no very far region near the equator where they had emerged at 20,000 years ago. 
Consequently, this great bound backwards could be explained by the fact that Homo sapiens sapiens expanded across the Earth following the replacement model and at his arrival to southern Europe he did not received any technological know-how from his predecessors who were completely or almost extinct. Namely, he produced stone tools with a sudden return to a general simplification. The explanation relative to SolutreanMagdalenian transition given by Breuil since the beginning of this century is in favor of my hypothesis. In fact, this great French archaeologist did not hesitate to declare: « if there is an event that would be certain in prehistory, it is the fact that the first Magdalenians are not evolved from Solutreans: they were many newcomers arrived at these places, as much they were unskilful in the art of hew and readjust flint as their predecessors excelled in it ...... » (Breuil, 1937).

Reaching the Southern Europe, modern humans have started from scratch for developing rapidly in only about 5,000 years, a technology more advanced than that of their predecessors. This is evident through the novel distinct technology "microlith" of the Magdalenian period that I consider as the first cultural period of modern man in Europe. Just before this Magdalenian period, at about 18,000 years ago, appeared in Levant a new culture distinct from that of the Paleolithic and designated Kebaran. It is characterized by microlithic tools and exhibits a remarkable degree of cultural change over a small period. Thus, it is reasonable to consider this kebaran culture as that of modern humans who had very likely reached Levant before. This suggestion agrees with a general scenario relating to successive first major expansions of modern humans deduced from analysis of genetic data (Chaabani, 2002).

The Magdalenian period in Europe began also by a new artistic creativity stage. In fact, the evolution of art was often considered as has been passed from simple preliminary drawings dated from about 35,000 years to the culmination of quality and visual sophistication of painted wall art of Magdalenian caves as that of Lascaux dated to about 16,000 years ago. 
But recent discoveries of marvellous caves particularly that of Chauvet dated to about 30,000 years ago, shown that this consideration was untrue (for review see Clottes, 2001). Thus, the art stage from 35,000 to 10,000 years in southern Europe could represent two independent periods rather than a unique period with gradual evolution. Namely, the art products of the stage between 35,000 and 18,000 years and those of the stage between 17,000 and 10,000 years, although appeared similar, they present some fine distinctive features. I can summarize these differences pointed out from the art products plenty found in Europe as follows. First, the art products of the last stage belonged to Homo sapiens sapiens, between 17,000 and 10,000 years, are evidently more homogeneous, often with high quality, and generally more realistic and evidently more colored (Clottes, 2001; Lima, 1996).

Second, during this period the geometric signs, often associated with the figurative representations, are evidently more numerous and more varied (Igarahi, 2002). If we accept that these symbols are somewhat graphic messages, they could represent, during the stage 35,000 - 18,000 years, words that Homo sapiens artist could pronounce intermittently. But, during the stage of 17,000-10,000 years their increase in number and in variants could reflect that Homo sapiens sapiens have developed a real complex spoken which needs much more words for forming preliminary sentences. This explanation is supported by the fact that the comparison of signs in different regions of the world shows a universal paradigm of these signs during the first period. While during the second they show some regional differentiation that reflects, very likely, the development of a real complex spoken and a preliminary regional linguistic differentiation. 


\section{- Concordance with dates of the appearance of social structure and spoken language}

Beside genetic and archaeological arguments that I have brought out, others could be gathered from the history analysis of the development of social structure and spoken language. In the course of Homo evolution, two types of genetic changes could be considered as necessary to the acquisition of a complex spoken language. The first one is in charge of anatomic modifications relative mainly to the larynx position, which enables the full pronunciation of spoken language. The second is among important genetic changes particularly on brain genes leading to the high biological and physiological complexity of the brain. This high level of complexity is necessary for the development of the complex spoken language and above all for having the reason of developing and using language. The proposition of this second type of genetic change is supported by the fact that language deficits in dyslexia are considered as consequence of genetic disorder.

Fossil record investigation shows that the anatomic modifications, necessary to give the main sounds produced by people today, have become fully effective among Homo peoples emerged at about 400,000 - 300,000 years ago (Laitmanm, 1983). Thus, according to my hypothesis Homo erctus inquietus was the earliest Homo who can pronounce a spoken language. He had begun, probably, to pronounce some symbolic designations, but stayed unable to develop a complex spoken language until the accomplishment of the second type of genetic change. The timing of this change could be estimated indirectly from that of the social complexity appearance, which could not come off without the development of a complex spoken language and vice versa.

The development of sedentary agricultural community appeared about 10000 years ago, has been preceded by that of the sedentary hunter-gatherer community. The site of Abu Hureyra in northern Syria occupied from 11,500 years ago gives a good example of sedentary hunter-gatherer community. 
In fact this community was composed of between 50 and 300 individuals, presents a fully social complexity absent in previous small nomadic hunter-gatherer bands (Legg and Rowley-Conwy, 1987). Therefore, the appearance of such social complexity, about 12,000 years ago, reflects a so recent complex spoken language development.

A support for this suggestion comes from several historical linguistic data, which show convincing similar estimations concerning the time of the ancestral languages development. Analyzing the relationships within the Afroasiatic language family, Fleming (1976) and Ehret (1979) have suggested independently that the seniority of the protovocabulary of this language family dated back to about 15,000 years ago. A similar date, 14,000 years ago, was proposed for the development of another protolanguage of a large language family named Sino-Caucasian (Starostine, 1989). Working separately, three Russian linguists have confirmed and / or completed the suggestions of Pedersen relative to the reconstitution of the 'Nostratic' considered as ancestral of many language families, particularly the Afroasiatic, the Altaic, the Uralic and the Indo-European. They have estimated independently the same date, 15,000 years ago, at which was developed and spoken this ancestral Nostratic language. However, the construction beginning of this proposed ancestral first language could date to about 20000 years ago (Shevoroskin, 1989, 1990; Dolgopolsky, 1988; Illich-Svitych, 1971, 1984).

All these consistent data agree entirely with my hypothesis and suggest that the second type of genetic changes, necessary to the complex spoken language development, have been affected among the last important genetic changes concerning particularly the brain genes. As stated above, these changes, accountable for a complete acquisition of the superior potential intellectual aptitude, appeared with the birth of modern man at about 20,000 years ago (Table 1). These recent dates of the development of complex spoken language and that of social complexity are inconsistent with the date of 120,000 years ago considered classically as that of modern man emergence. In other words, if the fossils dating to about 120,000 years are that of modern humans why social complexity and complex spoken language, have taken about 100,000 years for appearing in their behavior? 


\section{- Concordance with a demographic evolutionary analysis}

Within my hypothesis criticism, one can ask if it is possible that during a so short period (20,000 years), some few modern humans can give the extraordinary actual number of the earth's human inhabitants. As answer to this question, I present a demographic evolutionary analysis that reveals the possibility to reach the actual number of the earth's human inhabitants during a period shorter than 20,000 years (Table 3).

The number of the earth's human inhabitants at times before 1750 (253 years ago) was not decently estimated for lack of demographic information. Therefore, I have attempted to deduce approximate ones from corresponding hypothetical rates of population growth. I have estimated these rates on the basis of an evolutionary analysis of known rates relative to recent periods, taking into account a suitable continuity of the growth rate change correlated to life conditions.

As shown in Table 3 for the 1750-1650 period I have proposed an average annual growth rate of $0.42 \%$, which involves at 1650 a world population of 520 millions close to that of 500 millions proposed by Ohlin (1965). During the period between 10,000 and 2,000 years ago, I have considered that population grew at a rate of $0.10 \%$. This rate, equal to that previously considered for this period (Lewin, 1993), involves at 10,000 years ago a world population of about 14,800. While for the same period Ohlin gave a lower indefinite estimation of world population suspected to between 1 and 10 millions (Ohlin, 1965, mentioned in Cavalli-Sforza, 1993).

As regards the period between 17,000 and 10,000 years ago, I have proposed a growth rate of about $0.08 \%$, which is only slightly lower to that of $0.10 \%$ relating to the period between 10,000 - 2,000 years. On the contrary, an excessively low rate of about $0.0015 \%$ was previously assigned to the period between 17,000 and 10,000 years (e.g., Lewin, 1993) and considered generally as it was increased considerably, mainly under the agriculture effect, for reaching $0.10 \%$ at the beginning of Neolithic. But this consideration could not be supported for the following reasons. 
On the one hand, at the Neolithic transition, about 10,000 years ago, any possible relationship between the appearance of agriculture and the size of the world population could be suggested: First, because at this time the small world population distributed in the great part of the Old World showed a very low density unable to exert any pressure on the agriculture adoption. In fact, this adoption would be mainly the consequence of sedentism in places with agreeable life conditions. Therefore, the sedentary huntergatherer communities, appeared about 1,500 years before the Neolithic transition, could be considered as the cradle of a gradual adoption of plant and animal domestication. Second, because at the Neolithic transition, agriculture cannot lead to a so remarkable increase of the growth population rate from $0.0015 \%$ to $0.1 \%$. Namely prior to 10,000 years ago the number of world inhabitants is very low and, therefore, the natural source of food was satisfying.

In addition, there is no important change of life conditions which could be the cause of such remarkable increase of the growth population rate. In fact, after the most terrible episode, $22,000-20,000 \mathrm{BP}$, of the last glacial period, the climate had begun to be relatively less cold and more humid (Pons et al., 1991). Namely, it began to be gradually favorable to a good vegetation development coupling to an adequate presence of animals. In addition, the period of 17,000 - 10,000 years was known by a decisive amelioration of the hunting technique. Thus, the life conditions of modern man during the $17,000-10,000$ years period would be similar to those of the follower one, between 10,000 and 2,000 years, and consequently the growth rates relating to these two periods must not show an obvious difference. 
Table 3. Growth of world population since the modern man emergence

\begin{tabular}{|cc|l|c|}
\hline Time & $\begin{array}{l}\text { Estimated number of the } \\
\text { Earth's human inhabitant }\end{array}$ & $\begin{array}{c}\text { Average annual percentage } \\
\text { rate of growth during } \\
\text { successive periods }\end{array}$ \\
\hline
\end{tabular}

$\begin{array}{rrrr}17,000 & & \mathbf{5 5} & \mathbf{1 4 , 8 0 0} \\ 10,000 & & \mathbf{4 4 , 0 0 0 , 0 0 0} & \mathbf{0 . 1 0} \\ 2,000 & 0 & \mathbf{5 2 0 , 0 0 0 , 0 0 0} & \mathbf{0 . 1 5} \\ 350 & 1650 & 791,000,000 & \mathbf{0 . 4 2} \\ 250 & 1750 & 978,000,000 & 0.42 \\ 200 & 1800 & 1,262,000,000 & 0.51 \\ 150 & 1850 & 1,650,000,000 & 0.53 \\ 100 & 1900 & 2,506,000,000 & 0.84 \\ 50 & 1950 & 6,407,000,000 & 1.90 \\ 2 & 2000 & & \end{array}$

1 Source: For 1750 - 1950: Durand (1967); For 1950 - 2000: population estimates and projections available to the United Nations as of March 1974.

Present hypothetical estimations are in bold-faced number 


\section{References}

Adcock G. J., Dennis E. S., Easteal S., Huttlet G. A., Jermiin L. S., Peacock W. J., Thorne A., 2001 : Mitochondrial DNA sequences in ancient Australians: Implications for modern human origins. Proc Natl Acad Sci USA 98: 537-542.

Allain J.,1984 : Avant-propos. In: Centre National de la Recherche Scientifique (Ed): Etudes sur l'Abri Fritsch. Pp 7-12. Paris.

Bamble D. M., Lieberman D. E., 2004. Endurance running and evolution of Homo. Nature 432 : 345-352.

Bamshad M., Wooding S.P., 2003: Signatures of natural selection in the human genome. Nat Rev Genet 4: 99 - 111.

Brace C. L., 1964: The fate of classic Neanderthals: A consideration of hominid catastrophism. Current Anthropology 5: 3- 43.

Brauer G., 1984. A chronological approach to the origin of anatomically modern Homo sapiens in Africa and implications for the appearance of modern Europeans. In : F.H. Smith and F. Spencer (Ed.) The origins of modern human: a world survey of the fossil.. Pp 327-410. New York.

Breuil H., 1937: Les subdivisions du Paléolithique superieur. "Congrés International d'Anthropologie et d'Archeologie Préhistoriques", $14^{\text {ème }}$ sess, $2^{\text {ème }}$ ed., p. 40.

Cann R. L., Stoneking M., Wilson A. C., 1987: Mitochondrial DNA and human evolution. Nature 325: 31-36. 
Caramelli D., Lalueza-Fox C., Vernesi C., Lari M., Casoli A., Mallegni F. et al. 2003:

Evidence for a genetic discontinuity between Neandertals and 24,000-years-old anatomically modern Europeans. Proc Natl Acad Sci USA 100: 6593-6597.

Carbonell E., Moequera M., Ollé A. et al. 2003: Did the earliest mortuary practices take place more than 350000 years ago at Atapuerca? L'Anthropologie 107: 1-14.

Cavalli-Sforza L. L., Menozzi P., Piazza A., 1993: Demic Expansions and Human Evolution. Science 259: 639-646.

Clottes J., 2001: La Grotte Chauvet. L'Art des Origines. Paris: Seuil

Denaro M., Blanc H., Johnson M. J., Chen C. H., Wilmsen E., Cavalli-Sforza L. L., Wallace D. C., 1981: Ethnic variation in Hpa I endonuclease cleavage patterns of human mitochondrial DNA. Proc Natl Acad Sci USA 78: 5768-5772.

Dolgopolskey A., 1988: The Indo-European Homeland and Lexical Contacts of ProtoIndo-European with Other Languages. Mediterranean Review 3: 7-31.

Durand D., 1967: The modern expansion of world population. Proceedings of the American Philosophical Society 111: 137.

Ehret C., 1979: On the antiquity of agriculture in Ethiopia.. J Afr Hist 20: 161- 177.

Excoffier L., Langaney A., 1989: Origin and differentiation of human mitochondrial DNA. Am J Hum Genet 44: 73-85.

Fleming H. C., 1976: Sociology, ethnology and history in Ethiopia. Int J Hist 9: 248278. 
Foley R., 1988: Hominids, humans and hunter-gatherers an evolutionary perspective. In: T. Ingold et al. (Ed). Hunters and Gathers: History, Evolution and Social change. Oxford University Press.

Gish D. T., 1995: Evolution: the fossils still say no. Institute for Creation Research. El Cajon, CA.

Hammer M. F., 1995: A recent common ancestry for human Y chromosomes. Nature 378: 376-378.

Hammer M. F., Karafet T., Rasanayagam A., Wood E. T. et al., 1998: Out of Africa and back Again: Nested cladistic analysis of human Y chromosome variation. Mol Biol Evol 15: 427-441.

Harding R. M., Fullerton S. M., Griffiths R. C., Bond J. et al., 1997: Archaic African and Asian lineages in the genetic ancestry of modern humans. Am. J. Hum. Genet 60: 772-789.

Harris E. E., Hey I., 1999: X chromosome evidence for ancient human histories. Proc Natl Acad Sci USA 96: 3320-3324.

Hedges S. B., Kumar S., Tamura K., Stoneking M., 1992: Human origins and analysis of mitochondrial DNA sequences. Science 255: 737-739.

Igarashi J., 2002: Relations between figurative representations and signs in three Magdalenian caves: Les Combarelles I, Rouffignac (Périgord, France) and Altxerri (Spanish Basque). L'Anthropologie 106: 491-523.

Illich-Svitych V. M., 1971-1984: Opyt sravuenija nostraticheskix jazykov, 3 vols. Moscow. 
Ingman M., Kaessman H., Paaabo S., Gyllensten U., 2000: Mitochondrial genome variation and the origin of modern humans. Nature 408: 708-713.

Kaessman H., Heibig F., Haeseler A. V., Paaabo S., 1999: DNA sequence variation in a non coding region of low recombination on the human $\mathrm{X}$ chromosome. Nature Genet 22: 78-81.

Klein R. G., 1992: The archaeology of modern humans. Evolutionary Anthropology 1: $5-14$.

Kreitman M., 2000: Methods to detect selection in populations with applications to the human. Annu Rev Genomics Hum Genet 1: 539 - 559.

Krings M., Capelli C., Tschentscher F., Geisert H. et al., 2000: A view of Neandertal genetic diversity. Nat Genet 26: 144-146.

Laitmaum J. T., 1983: The anatomy of speech. Natural History, August: 20-27.

Laughlin W. S., 1963: Eskimos and Aleuts: Their origins and Evolution. Science 142: 633-645.

Legg A. J., Rowley- Conwy P. A., 1987: Gazelle killing in Stone Age Syria. Scientific American.

Lewin R., 1988: A revolution of idea in agricultural origins. Science 240: 984-986.

Lewin R., 1993: Human Evolution. Blackwell Scientific Publications, Boston. 
Lima P., 1996: Naturalistes de la préhistoire: Les peintres du Magdalénien auraient cherché à représenter la réalité. La Recherche 291: 44-45.

Lowell T. V., Heusser C. J., Andersen B. G. et al., 1995: Interhemispheric correlation of Late Pleistocene glacial events. Science 269: 1541-1549.

Ohlin G., 1965: Historical out line of world Population Growth. Basic paper presented to UNIESP

Ovchinnikov I. V., Gotherstrom A., Romanova G. P., Kharitonov V. M., Liden K., Goodwin W., 2000: Molecular analysis of Neanderthal DNA from the northern Caucasus. Nature 404: 490-493.

Maddison D. R., Ruvolo M., Swofford D. L., 1992: Geographic origins of human mitochondrial DNA: phylogenetic evidence from control region sequences. Systematic Biol 41: 111-124.

Pollard K. S. et al., 2006 : An RNA gene expressed during cortical development evolved rapidly in humans. Nature $443: 167-172$.

Pons A., de Beaulieu J. L., Guiot J., Reille M., 1991: Le pollen remonte le temps climatique. La Recherche 231: 518-520.

Protsch R., 1975: The absolute dating of Upper Pleistocene sub-Saharan fossil hominids and their place in human evolution. J Hum Evol 2: 529-536.

Relehford J. H., 2001 : Ancient DNA and the origin of Modern humans. Proc Natl Acad Sci USA 98: 390- 391 
Ruhlen M., 1998: Toutes parentes, toutes differentes. La Recherche 306: 68-75.

Shevoshkin V., 1989: Reconstructing Languages and Cultures. V. Shevoshkin (Ed) Bochum: Brockmeyer.

Shevoshkin V., 1990: The mother tongue. The Sciences 3: 20-27.

Solecki R. S., 1957: Shanidar Cave. Scientific American 5: 60-63.

Spoor F., Wood B., Zonneveld F., 1994: Implications of early hominid labyrinthine morphology for evolution of human bipedal locomotion.. Nature 369: 645-648.

Starostin S., 1989: Nostratic and Sino-Caucasian. In: V. Shevoshkin (Ed).

Reconstructing Languages and Cultures. Bochum: Brockmeyer.

Stringer C., 2003: Human evolution: Out of Ethiopia. Nature 423: 692-695.

Tattersall I., 1992: Species concepts and species recognition in human evolution. J. Hum Evol 22: 341-349.

Templeton A. R., 2002: Out of Africa again and again. Nature 416: 45-51.

Thoma A., 1973: New evidence of the polycentric evolution of Homo sapiens, J Hum Evol 2: 529-536.

Vallender E. J., Lahn B. T., 2004: Positive selection on the human genome. Human Molecular Genetics. 13: 245 - 254.

Voight B.F. et al. 2006 : A map of recent positive selection in the human genome. PLoS Biol 4(3) : e72. 
Wang E. T. et al., 2006 : Global landscape of recent inferred Darwinian selection for Homo sapiens. PNAS 103: $135-140$.

White T. D., Asfaw B., Degusta D., Gilbert H., Richards G. D., Suwa G., Howell C., 2003: Pleistocene Homo sapiens from Middle Awash, Ethiopia. Nature 423: 742-747.

Wolpoff M. H., 1986: Stasis in the interpretation of evolution in Homo erectus. Paleobiology 12: 325-328.

Wood B. A., Collard M., 1999: The Human Genus. Science 284: 65-71.

Zhang I., Rosenberg H. E., 2000: Sequence variation at two eosinophil-associated ribonuclease loci in humans. Genetics 156: 1949-1958. 